\title{
Outcome during and after anticoagulant therapy in cancer patients with incidentally found pulmonary embolism
}

\author{
Marisa Peris ${ }^{1}$, David Jiménez ${ }^{2}$, Ana Maestre ${ }^{3}$, Carme Font ${ }^{4}$, Alfonso J. Tafur ${ }^{5}$, \\ Lucia Mazzolai ${ }^{6}$, Belén Xifre ${ }^{7}$, Andris Skride ${ }^{8}$, Francesco Dentali (109, \\ Manuel Monreal ${ }^{10}$ and the RIETE Investigators ${ }^{11}$
}

\begin{abstract}
Affiliations: ${ }^{1}$ Dept of Internal Medicine, Consorcio Hospitalario Provincial de Castellón, Ceu Cardenal Herrero University, Castellón, Spain. ${ }^{2}$ Respiratory Dept, Ramón y Cajal Hospital and Instituto Ramón y Cajal de Investigación Sanitaria, Madrid, Spain. ${ }^{3}$ Dept of Internal Medicine, Hospital Universitario de Vinalopó, Alicante, Spain. ${ }^{4}$ Dept of Medical Oncology, IDIBAPS/Translational Genomics and Targeted Therapeutics in Solid Tumors, Hospital Clinic de Barcelona, Barcelona, Spain. ${ }^{5}$ Division of Vascular Surgery, Evanston Hospital, NorthShore University HealthSystem, Chicago, IL, USA. ${ }^{6}$ Dept of Angiology, Centre Hospitalier Universitaire Vaudois, Lausanne, Switzerland. ${ }^{7}$ Dept of Internal Medicine, Hospital El Vendrell, Tarragona, Spain. ${ }^{8}$ Dept of Cardiology, Ospedale Pauls Stradins Clinical University Hospital, Riga, Latvia. ${ }^{9}$ Dept of Clinical and Experimental Medicine, University of Insubria, Varese, Italy. ${ }^{10}$ Dept of Internal Medicine, Hospital de Badalona Germans Trias i Pujol, Universidad Católica de Murcia, Murcia, Spain. ${ }^{11}$ For a full list of the RIETE investigators please see the Acknowledgements.
\end{abstract}

Correspondence: Manuel Monreal, Servicio de Medicina Interna, Hospital Universitari Germans Trias i Pujol, 08916 Badalona, Barcelona, Spain. E-mail: mmonreal.germanstriasagencat.cat

ABSTRACT Current guidelines suggest treating cancer patients with incidental pulmonary embolism comparably to patients with symptomatic pulmonary embolism.

We used the Registro Informatizado de Enfermedad TromboEmbólica (RIETE) registry to compare the rate of major bleeding and symptomatic pulmonary embolism during the course of anticoagulation and after its discontinuation in cancer patients with incidental pulmonary embolism.

As of March 2016, 715 cancer patients with incidental pulmonary embolism had been enrolled in RIETE. During the course of anticoagulant therapy (mean 235 days), the rate of major bleeding was higher than the rate of symptomatic pulmonary embolism (10.1 (95\% CI 7.48-13.4) versus 3.17 (95\% CI 1.80-5.19) events per 100 patient-years, respectively), and the rate of fatal bleeding was higher than the rate of fatal pulmonary embolism (2.66 (95\% CI 1.44-4.52) versus 0.66 (95\% CI 0.17-1.81) deaths per 100 patient-years, respectively). After discontinuing anticoagulation (mean follow-up 117 days), the rate of major bleeding was lower than the rate of symptomatic pulmonary embolism (3.00 (95\% CI 1.10-6.65) versus 8.37 (95\% CI 4.76-13.7) events per 100 patient-years, respectively); however, there were no differences in the rate of fatal events at one death each.

The risk/benefit ratio of anticoagulant therapy in cancer patients with incidental pulmonary embolism is uncertain and must be evaluated in further studies.

@ERSpublications

The risk/benefit ratio of anticoagulant therapy in cancer patients with incidentally found PE is uncertain http://ow.ly/2eq5302gWmr educational grant. We also express our gratitude to Bayer Pharma AG for supporting this registry. Bayer Pharma AG's support was limited to the part of RIETE outside Spain, which accounts for a $22.87 \%$ of the total patients included in the RIETE Registry. Funding information for this article has been deposited with the Open Funder Registry.

Conflict of interest: None declared.

Copyright CERS 2016 


\section{Introduction}

Patients with active cancer frequently undergo routine imaging studies, which usually include chest computed tomography (CT) scans, to assess the extent of the malignancy, the response to cancer therapy or to screen for metastases. With the widespread use of CT testing, the detection of incidental pulmonary embolism has become increasingly common $[1,2]$. Current guidelines on antithrombotic therapy from the American College of Chest Physicians (ACCP) and the American Society of Clinical Oncology (ASCO) suggest treating patients with incidental pulmonary embolism as comparable patients with symptomatic pulmonary embolism [3, 4]. However, supporting evidence for this recommendation is limited by the small size of the studies [5-14]. Recently, VAN DER HULLE et al. [15] evaluated the outcome in 926 cancer patients with incidental pulmonary embolism from 11 cohorts, and found that they had a high risk of symptomatic pulmonary embolism events, particularly when left untreated. These findings may support the guidelines' recommendations. However, the follow-up period was limited to only 6 months, and there was no information on the quality of anticoagulation, the consequences of pulmonary embolism or bleeding events or the outcome after discontinuing anticoagulant therapy.

The Registro Informatizado de Enfermedad TromboEmbólica (RIETE) registry is an ongoing, multicentre, international (Spain, Belgium, Canada, Czech Republic, Ecuador, France, Greece, Israel, Italy, Latvia, Portugal, Republic of Macedonia and Switzerland) observational registry of consecutive patients with objectively confirmed acute venous thromboembolism (VTE). Data from this registry have been used to evaluate outcomes after acute VTE, such as the frequency of recurrent VTE, bleeding and mortality and risk factors for these outcomes [16-19]. The aim of the current study was to compare the rate of symptomatic VTE and major bleeding events appearing during the course of anticoagulant therapy and after its discontinuation in patients with active cancer and incidental pulmonary embolism.

\section{Patients and methods}

Inclusion criteria

Consecutive patients with incidental pulmonary embolism at helical CT scan were enrolled in RIETE. All patients provided written or oral consent for participation in the registry, in accordance with local ethics committee requirements. This analysis was approved by the Ethics Committees of the UZ Gasthuisberg Hospital in Leuven, Belgium (B70721111790) and the Hospital Clinic of Barcelona, Spain (Reg. HCB/2015/0386).

Physicians participating in the RIETE registry made all efforts to enrol consecutive patients. Data were recorded on to a computer-based case report form at each participating hospital and submitted to a centralised coordinating centre through a secure website. The coordinating centre assigned patients with a unique identification number to maintain patient confidentiality and was responsible for all data management.

\section{Study design}

For this study, only patients with active cancer diagnosed with incidental pulmonary embolism were considered. Active cancer was defined as newly ( $<3$ months before) diagnosed cancer, metastatic cancer or cancer that was being treated (i.e. surgery, chemotherapy, radiotherapy, support therapy or combined therapies). Incidental pulmonary embolism was defined as pulmonary embolism detected on a CT scan ordered for reasons other than a clinical suspicion of pulmonary embolism [20]. We compared their clinical characteristics, chest CT scan findings, treatment and outcome during the course of anticoagulant therapy and after its discontinuation according to the presence or absence of metastases. CT scan findings were classified as centrally located thrombi (defined as a central or lobar thrombus location) and more peripherally located thrombi (defined as a segmental or sub-segmental thrombus location).

The major outcome was the rate of symptomatic, objectively confirmed pulmonary embolism and major bleeding occurring during the course of anticoagulation and after its discontinuation. Bleeding complications were classified as "major" if they were overt and required a transfusion of two units of blood or more, or were retroperitoneal, spinal or intracranial, or when they were fatal. Secondary outcomes were acute deep vein thrombosis (DVT) minor bleeding, fatal pulmonary embolism and fatal bleeding. Each episode of clinically suspected pulmonary embolism or DVT was investigated by ultrasonography, contrast venography, lung scanning, helical CT scan or pulmonary angiography as appropriate. Minor bleeding was defined as any overt bleed requiring medical assistance but not filling the criteria for major bleeding. Fatal pulmonary embolism, in the absence of autopsy, was defined as any death appearing within 10 days after symptomatic pulmonary embolism diagnosis, in the absence of any alternative cause of death. Fatal bleeding was defined as any death occurring within 10 days of a major bleeding episode, in the absence of an alternative cause of death.

\section{Baseline variables}

The following parameters are routinely recorded in RIETE: patient's baseline characteristics; clinical status including any coexisting or underlying conditions; risk factors for VTE; laboratory data; treatment received 
upon VTE diagnosis (drugs, doses and duration); and the outcome during the course of anticoagulant therapy. Immobilised patients were defined as non-surgical patients who had been immobilised (i.e., total bed rest with bathroom privileges) for $\geqslant 4$ days in the 2 -month period prior to VTE diagnosis. Surgical patients were defined as those who underwent a surgical intervention in the 2 months prior to VTE. Recent bleeding was defined as a major bleeding episode $<30$ days prior to VTE.

\section{Treatment and follow-up}

Patients were managed according to the clinical practice of each participating hospital (i.e., there was no standardisation of treatment). Patients were followed-up for at least 3 months in the outpatient clinic. During each visit, any signs or symptoms suggesting symptomatic VTE recurrences or bleeding complications were noted. Each episode of clinically suspected recurrent VTE was investigated by repeat compression ultrasonography, lung scanning, helical CT scan or pulmonary angiography as appropriate. Most outcomes were classified as reported by the clinical centres. However, if staff at the coordinating centre were uncertain how to classify a reported outcome, that event was reviewed by a central adjudicating committee (less than $10 \%$ of events).

\section{Data collection and monitoring}

The primary investigator ensured a consecutive enrolment of qualified patients. The data collected were recorded electronically using the RIETE report form accessible to each of the participating hospitals and medical offices and were submitted securely to the central coordinating centre. Data were encrypted to ensure confidentiality and security and patients were assigned a unique number by the study's coordinating centre. Quality measures were utilised regularly and electronically documented to expose errors or inconsistencies.

\section{Statistical analysis}

We used a t-tests and the Chi-squared test (or Fisher's exact test where appropriate) to compare continuous or categorical variables. Then, we carried out a multivariable analysis through a logistic regression model trying to identify independent predictors for major bleeding and for symptomatic pulmonary embolism during the course of anticoagulant therapy or after its discontinuation. Covariates entering in the model were selected by a significance level of $\mathrm{p}<0.10$ on univariable analysis, or by a wellknown association reported in the literature. SPSS software (version 20, SPSS Inc. Chicago, IL, USA) was used for the statistical management of the data, and a two-sided $\mathrm{p}<0.05$ was considered to be statistically significant.

\section{Results}

As of March 2016, 715 patients with active cancer and incidental pulmonary embolism had been enrolled in RIETE. Of these, 451 (63\%) had metastatic cancer. Patients with metastases were significantly younger and less likely to have recent surgery but more likely to have anaemia or thrombocytosis than those without metastases (table 1). There were no differences in heart rate, respiratory rate or blood gases between both subgroups or in the proportion of patients with peripheral (versus central) arteries involved on CT scan. As to the site of cancer, patients with metastases were more likely to have lung or breast cancer and less likely to have bladder or cerebral cancer (table 2). Most patients (98\%) were initially treated with low-molecular-weight heparin (LMWH), with similar doses between both subgroups. Then, 617 (86\%) received long-term LMWH therapy, 63 (8.8\%) switched to vitamin K antagonists and eight (1.1\%) received other drugs. Patients with metastatic cancer most likely received long-term therapy with LMWH than those without metastases (OR 4.14; 95\% CI 2.63-6.50).

\section{Outcome during the course of anticoagulant therapy}

During the course of anticoagulation (mean 235 days), 14 patients presented with symptomatic pulmonary embolism (three died of the pulmonary embolism), six with DVT, 45 had major bleeding (12 died of bleeding, eight bled in the brain), 32 had non-major, clinically relevant bleeding and 197 died (table 3). The rate of major bleeding was three-fold higher than the rate of symptomatic pulmonary embolism (10.1 (95\% CI 7.48-13.4) versus 3.17 (95\% CI 1.80-5.19) events per 100 patient-years, respectively) (figure 1 and table 4). Moreover, the rate of non-major bleeding was five-fold higher than the rate of symptomatic DVT (7.52 (95\% CI 4.48-11.3) versus 1.34 (95\% CI 0.54-2.78) events per 100 patient-years, respectively), and the rate of fatal bleeding was four-fold higher than the rate of fatal pulmonary embolism (2.66 (95\% CI 1.44-4.52) versus 0.66 (95\% CI $0.17-1.81$ ) deaths per 100 patient-years, respectively). Patients with metastatic cancer had a higher rate of major (OR 2.84; 95\% CI 1.41-6.24) and fatal (OR 7.72; 95\% CI 1.32-16.8) bleeding than those without metastases, with no differences in the rate of VTE or non-major bleeding events. Pulmonary embolism was the eight most common cause of death (table 3 ). 


\begin{tabular}{|c|c|c|c|}
\hline & Metastases & No metastases & OR $(95 \% \mathrm{CI})$ or $\mathrm{p}$-value \\
\hline Patients n & 451 & 264 & \\
\hline \multicolumn{4}{|l|}{ Clinical characteristics } \\
\hline Age years & $65 \pm 11$ & $70 \pm 11$ & \\
\hline Male & 268 (59) & $165(63)$ & $0.88(0.64-1.20)$ \\
\hline Body weight kg & $71 \pm 12$ & $74 \pm 15$ & \\
\hline \multicolumn{4}{|l|}{ Additional risk factors for VTE } \\
\hline Surgery & $44(9.8)$ & $40(15)$ & $0.61(0.38-0.96)$ \\
\hline Immobility $\geqslant 4$ days & $65(14)$ & $39(15)$ & $0.97(0.63-1.49)$ \\
\hline Oestrogen therapy & 24 (5.3) & $11(4.2)$ & $1.29(0.62-2.68)$ \\
\hline None of the above & $322(71)$ & 179 (68) & $1.19(0.85-1.65)$ \\
\hline Prior VTE & $31(6.9)$ & $21(8.0)$ & $0.85(0.48-1.52)$ \\
\hline \multicolumn{4}{|l|}{ Comorbidities } \\
\hline Chronic lung disease & $49(11)$ & $29(11)$ & $0.99(0.61-1.61)$ \\
\hline Chronic heart failure & $19(4.2)$ & $13(4.9)$ & $0.85(0.41-1.75)$ \\
\hline Creatinine clearance $30-60 \mathrm{~mL} \cdot \mathrm{min}^{-1}$ & $94(21)$ & $66(25)$ & $0.79(0.55-1.13)$ \\
\hline Creatinine clearance $<30 \mathrm{~mL} \cdot \mathrm{min}^{-1}$ & $8(1.8)$ & $8(3.0)$ & $0.58(0.21-1.56)$ \\
\hline Recent major bleeding & $13(2.9)$ & 14 (5.3) & $0.53(0.25-1.15)$ \\
\hline Anaemia & $294(65)$ & $143(54)$ & $1.58(1.16-2.16)$ \\
\hline WBC $>11000$ cells $\cdot \mu \mathrm{L}^{-1}$ & $87(19)$ & $47(18)$ & $1.10(0.75-1.63)$ \\
\hline Platelet count $<100000$ per $\mu \mathrm{L}$ & $16(3.5)$ & $8(3.0)$ & $1.18(0.50-2.79)$ \\
\hline Platelet count $>450000$ per $\mu \mathrm{L}$ & $34(7.5)$ & $10(3.8)$ & $2.07(1.01-4.26)$ \\
\hline \multicolumn{4}{|l|}{ Respiratory tests } \\
\hline Respiratory rate breaths $\cdot \min ^{-1}(n=358)$ & $18 \pm 3$ & $17 \pm 6$ & 0.326 \\
\hline Respiratory rate $>20$ breaths $\cdot \min ^{-1}$ & $22(9.0)$ & $12(11)$ & $0.83(0.40-1.74)$ \\
\hline Heart rate beats $\cdot \min ^{-1}(n=633)$ & $82 \pm 15$ & $84 \pm 19$ & 0.168 \\
\hline Heart rate $>110$ beats $\cdot \mathrm{min}^{-1}$ & $20(5.0)$ & $20(8.7)$ & $0.55(0.29-1.05)$ \\
\hline Oxygen saturation $\%(n=197)$ & $95 \pm 7$ & $94 \pm 6$ & 0.581 \\
\hline Oxygen saturation $<90 \%$ & $7(6.1)$ & $6(7.2)$ & $0.84(0.27-2.60)$ \\
\hline \multicolumn{4}{|l|}{ Chest CT findings } \\
\hline \multicolumn{4}{|l|}{ Largest arteries involved } \\
\hline Segmental or subsegmental & $123(27)$ & $84(32)$ & $0.80(0.58-1.12)$ \\
\hline Pulmonary or lobar & $266(59)$ & 129 (49) & $1.50(1.11-2.04)$ \\
\hline Not reported & $62(14)$ & $51(19)$ & $0.67(0.44-1.00)$ \\
\hline
\end{tabular}

Data are presented as mean \pm SD or $n(\%)$, unless otherwise stated. VTE: venous thromboembolism; WBC: white blood cell count; CT: computed tomography.

Outcome in the absence of anticoagulant therapy

The clinical outcome without anticoagulation was available for 229 patients: 13 did not receive anticoagulant therapy at all and 216 were followed-up after discontinuing therapy. Of these, 136 (59\%) had metastases. During a mean follow-up of 117 days, 14 patients presented with symptomatic pulmonary embolism, 13 with DVT, five had major bleeding, four had non-major bleeding and 84 died (table 5). The rate of major bleeding was three-fold lower than the rate of symptomatic pulmonary embolism $(3.00(95 \%$ CI 1.10-6.65) versus 8.37 (95\% CI 4.76-13.7) events per 100 patient-years, respectively), and the rate of non-major bleeding was also three-fold lower than the rate of DVT (2.40 (95\% CI 0.76-5.78) versus 7.17 (95\% CI 3.89-12.2) events per 100 patient-years, respectively). However, there was one fatal pulmonary embolism and one fatal bleeding. The rate of symptomatic pulmonary embolism was five-fold higher in patients with metastases than in those without (OR 5.13; 95\% CI 1.30-33.8), with no differences in the rate of DVT or bleeding events.

On multivariable analysis, patients with severe renal insufficiency (HR 3.61; 95\% CI 1.14-11.5), leukocyte count $>11000$ cells $\mu \mathrm{L}^{-1}$ (HR 3.03; 95\% CI 1.55-5.93), metastatic cancer (HR 3.03; 95\% CI 1.55-5.93), ovarian cancer (HR 5.38; 95\% CI 1.69-17.1) or renal cancer (HR 4.23; 95\% CI 1.24-14.4) were at increased risk for major bleeding (table 6). Those with colorectal cancer were at lower risk for symptomatic pulmonary embolism.

\section{Discussion}

Current guidelines on antithrombotic therapy suggest treating cancer patients with incidental pulmonary embolism as similar patients with symptomatic pulmonary embolism $[3,4]$. In our cohort, the rate of major bleeding during the course of anticoagulant therapy was three-fold higher than the rate of symptomatic 
TABLE 2 Sites of cancer and treatment according to the presence or absence of metastases

\begin{tabular}{|c|c|c|c|}
\hline & Metastases & No metastases & OR $(95 \% \mathrm{CI})$ or $\mathrm{p}$-value \\
\hline Patients n & 451 & 264 & \\
\hline \multicolumn{4}{|l|}{ Site of cancer } \\
\hline Colorectal & $89(20)$ & $67(25)$ & $0.72(0.50-1.04)$ \\
\hline Lung & 114 (25) & $33(13)$ & $2.37(1.55-3.61)$ \\
\hline Breast & $41(9.1)$ & $13(4.9)$ & $1.93(1.01-3.67)$ \\
\hline Gastric & $31(6.9)$ & $15(5.7)$ & $1.23(0.65-2.31)$ \\
\hline Pancreas & $29(6.4)$ & $10(3.8)$ & $1.75(0.84-3.64)$ \\
\hline Kidney & $21(4.7)$ & $13(4.9)$ & $0.94(0.46-1.92)$ \\
\hline Bladder & $13(2.9)$ & $20(7.6)$ & $0.36(0.18-0.74)$ \\
\hline Ovary & 16 (3.5) & $7(2.7)$ & $1.35(0.55-3.33)$ \\
\hline Prostate & 15 (3.3) & $8(3.0)$ & $1.10(0.46-2.63)$ \\
\hline Melanoma & $19(4.2)$ & $2(0.76)$ & $5.76(1.33-24.9)$ \\
\hline Uterus & $9(2.0)$ & $6(2.3)$ & $0.88(0.31-2.49)$ \\
\hline Oesophagus & $10(2.2)$ & 4 (1.5) & $1.47(0.46-4.75)$ \\
\hline Cerebral & $4(0.89)$ & $9(3.4)$ & $0.25(0.08-0.83)$ \\
\hline Other & $40(8.0)$ & $57(16)$ & $0.35(0.23-0.55)$ \\
\hline \multicolumn{4}{|l|}{ Initial therapy } \\
\hline LMWH & $433(96)$ & 246 (93) & $1.76(0.90-3.45)$ \\
\hline Mean LMWH doses IU $\cdot \mathrm{kg}^{-1} \cdot$ day $^{-1}$ & $163 \pm 42$ & $165 \pm 43$ & 0.496 \\
\hline Unfractionated heparin & $6(1.3)$ & $11(4.2)$ & $0.31(0.11-0.85)$ \\
\hline Other & $3(0.67)$ & $3(1.1)$ & $0.58(0.12-2.91)$ \\
\hline No anticoagulant therapy & $9(2.0)$ & $4(1.5)$ & $1.32(0.40-4.34)$ \\
\hline Vena cava filter & $9(2.0)$ & $19(7.2)$ & $0.26(0.12-0.59)$ \\
\hline \multicolumn{4}{|l|}{ Long-term therapy } \\
\hline Vitamin $\mathrm{K}$ antagonists & $11(2.4)$ & $52(20)$ & $0.10(0.05-0.20)$ \\
\hline LMWH & 418 (93) & 199 (75) & $4.14(2.63-6.50)$ \\
\hline Mean LMWH doses IU $\cdot \mathrm{kg}^{-1} \cdot$ day $^{-1}$ & $150 \pm 39$ & $144 \pm 41$ & 0.097 \\
\hline LMWH doses $>150 \mathrm{IU} \cdot \mathrm{kg}^{-1} \cdot \mathrm{day}^{-1}$ & $213(51)$ & $85(43)$ & $1.39(0.98-1.96)$ \\
\hline Other & $5(1.1)$ & $3(1.1)$ & $0.98(0.23-4.11)$ \\
\hline No anticoagulant therapy & $17(3.8)$ & $10(3.8)$ & $0.99(0.45-2.21)$ \\
\hline \multicolumn{4}{|l|}{ Cancer therapy } \\
\hline Chemotherapy & $278(62)$ & $88(33)$ & $3.21(2.34-4.42)$ \\
\hline Radiotherapy & $46(10)$ & $22(8.3)$ & $1.25(0.73-2.13)$ \\
\hline Hormonal therapy & $27(6.0)$ & $15(5.7)$ & $1.06(0.55-2.03)$ \\
\hline
\end{tabular}

Data are presented as $\mathrm{n}(\%)$ or mean $\pm \mathrm{SD}$, unless otherwise stated. $\mathrm{LMWH}$ : low-molecular-weight heparin.

pulmonary embolism (45 versus 14 events, respectively), the rate of non-major bleeding was five-fold higher than the rate of symptomatic DVT (32 versus six events, respectively) and the rate of fatal bleeding was four-fold higher than the rate of fatal pulmonary embolism (12 versus three deaths, respectively). After discontinuing anticoagulant therapy, the rate of major bleeding was three-fold lower than the rate of symptomatic pulmonary embolism (five versus 14 events, respectively), the rate of non-major bleeding was also three-fold lower than the rate of symptomatic DVT (four versus 12 events, respectively) and the rate of fatal bleeding was similar to the rate of fatal pulmonary embolism (one death each).

We identified patients at high risk for major bleeding (those with renal insufficiency, anaemia, leukocytosis or metastases), but failed to identify those at high risk for symptomatic pulmonary embolism (only patients with colorectal cancer were found to be at increased risk). Thus, we can only state that the risk/ benefit ratio of anticoagulant therapy in cancer patients with incidentally found pulmonary embolism is uncertain and must be evaluated in further studies.

Our data disagree with those from a recent study using individual patient data from studies identified by a systematic literature search [15]. In 926 cancer patients with incidental pulmonary embolism from 11 cohorts in different countries, weighted pooled 6-month rates of recurrent VTE (including both DVT and pulmonary embolism) and major bleeding were similar. This notable difference with our data may be likely explained by differences in clinical characteristics, quality of anticoagulation or duration of anticoagulant therapy. Unfortunately however, this information was unavailable in the study by VAN DER HulLE et al. [15]. There was no information either on the clinical consequences of symptomatic pulmonary embolism or bleeding (particularly mortality) nor on the outcome after discontinuing anticoagulant therapy. 
TABLE 3 Clinical outcome during the course of anticoagulation (patients not receiving anticoagulation were not considered)

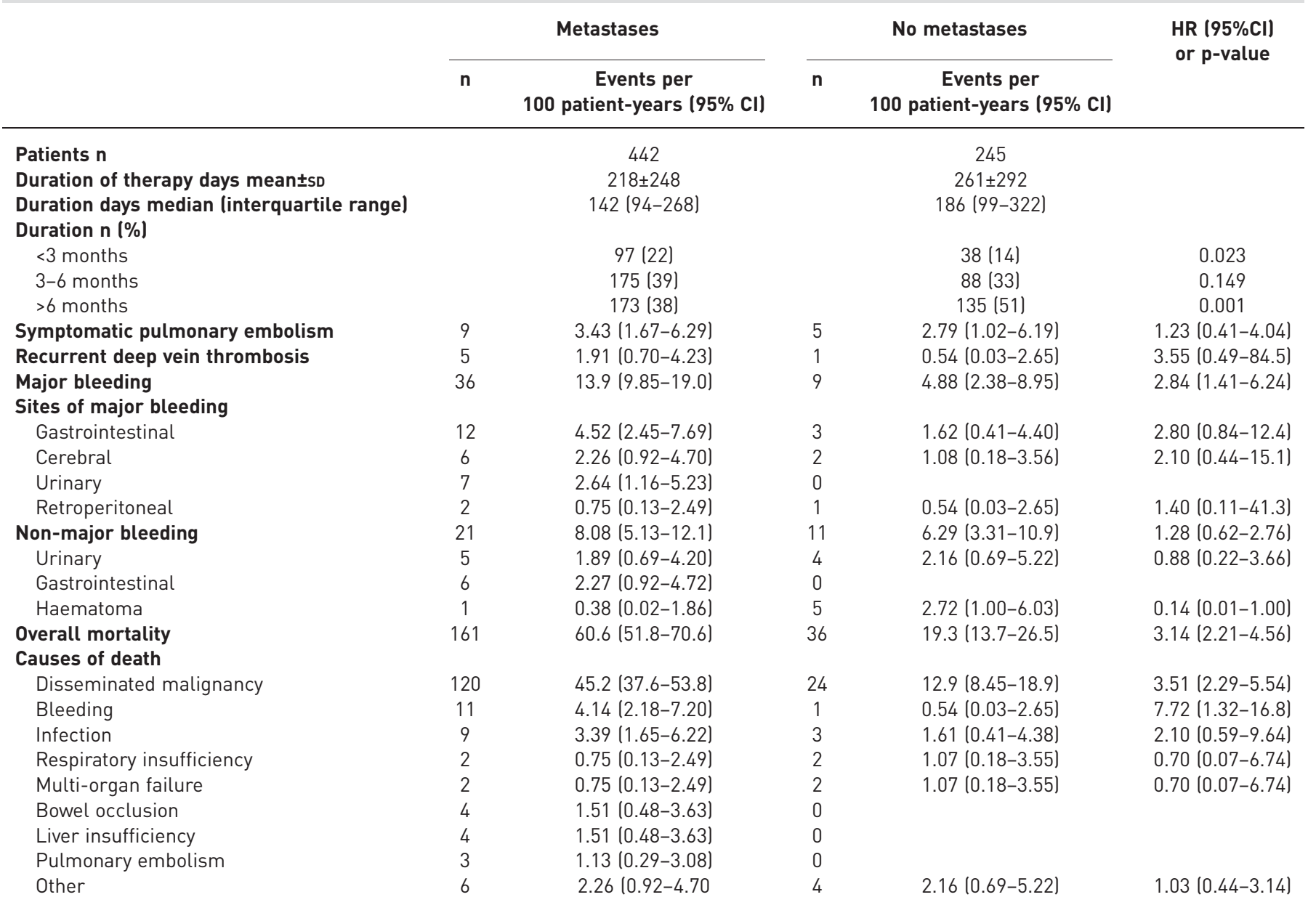

The present study however, has potential limitations. Firstly, since RIETE is an observational registry (and not a randomised trial) our data are hypothesis-generating. They might be a useful basis for future controlled clinical trials comparing different therapeutic strategies, but we should be extremely cautious in suggesting changes in treatment strategies just because of uncontrolled registry data. Secondly, patients were not treated with a standardised anticoagulant regimen; treatment varied with local practice, and is likely to have been influenced by a physician's assessment of a patient's risk of bleeding. Thirdly, to fulfil the definition of fatal pulmonary embolism, it is mandatory in RIETE that patients must first experience an

FIGURE 1 Cumulative rates of major bleeding and symptomatic pulmonary embolism (PE) events appearing during the course of anticoagulant therapy, according to the presence or absence of metastases (first 12 months).

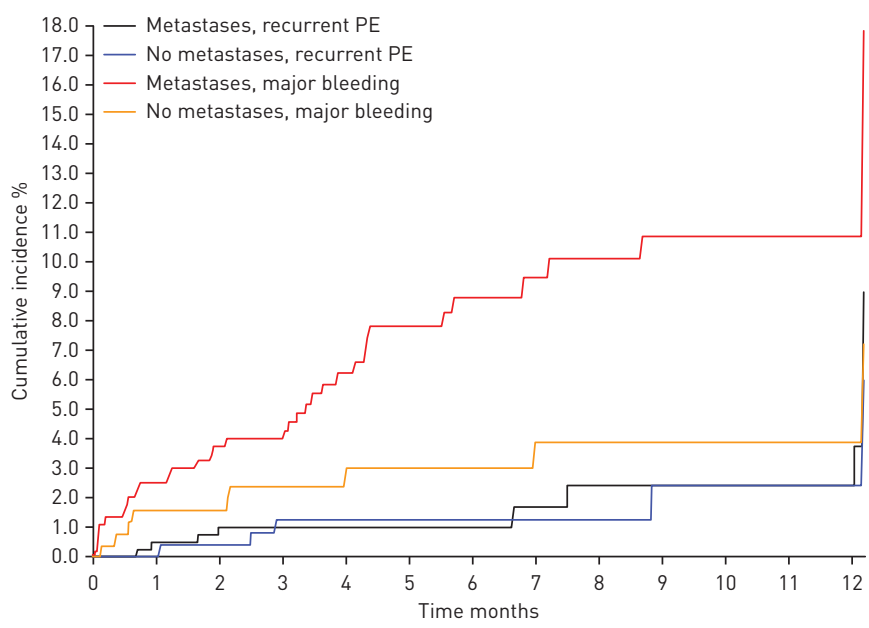


TABLE 4 Cumulative rates of major bleeding and symptomatic pulmonary embolism events appearing during the course of anticoagulant therapy, according to the presence or absence of metastases (first 12 months)

\begin{tabular}{lccccc} 
& \multicolumn{5}{c}{ Day } \\
\cline { 2 - 6 } & $\mathbf{7}$ & $\mathbf{3 0}$ & $\mathbf{9 0}$ & $\mathbf{1 8 0}$ & $\mathbf{3 6 0}$ \\
\hline $\begin{array}{l}\text { Patients at risk } \\
\quad \text { Metastases }\end{array}$ & 442 & 426 & 379 & 259 & 124 \\
$\quad$ No metastases & 260 & 253 & 236 & 177 & 96 \\
$\quad \begin{array}{l}\text { Major bleeding } \\
\quad \text { Metastases }\end{array}$ & $6(1.35)$ & $11(2.52)$ & $17(4.02)$ & $30(8.81)$ & $33(10.9)$ \\
$\quad$ No metastases & $1(0.39)$ & $4(1.58)$ & $6(2.4)$ & $7(3)$ & $8(3.88)$ \\
$\quad \begin{array}{l}\text { Symptomatic pulmonary embolism } \\
\quad \text { Metastases }\end{array}$ & 0 & $2(0.48)$ & $4(1)$ & $4(1)$ & $6(2.42)$ \\
$\quad$ No metastases & 0 & 0 & $3(1.27)$ & $3(1.27)$ & $4(2.45)$
\end{tabular}

Data are presented as $\mathrm{n}$ or $\mathrm{n}(\%)$.

objectively confirmed pulmonary embolism event followed by death within the first 10 days. Thus, all sudden unexplained deaths which are usually considered as "likely" fatal pulmonary embolism in many randomised trials are not considered in this analysis, and our study may have underestimated some patients who may have died of pulmonary embolism, especially after hospital discharge. However, a sudden death may also be due to a cerebral bleeding. Finally, patients in the RIETE database were selected in several different countries. The variability of practices in different countries could potentially affect the study outcomes. For instance, the dosing and timing of pharmacological treatment can vary according to each individual's country's pattern of practice, underlying disease process and/or presence or absence of a diagnosed malignancy. Furthermore, a variety of practitioners entered data into the registry, which may lend itself to potential inaccuracies in the data being reported. The main strengths of our observation are the high

TABLE 5 Clinical outcome after discontinuing anticoagulant therapy (patients not receiving anticoagulation are also included)

\begin{tabular}{cc} 
& Metastases \\
\hline $\mathrm{n} \quad 100$ patient-years $(95 \% \mathrm{Cl})$
\end{tabular}

\begin{tabular}{cc} 
& No metastases \\
\hline $\mathrm{n} \quad$ Events per \\
& 100 patient-years $(95 \% \mathrm{Cl})$
\end{tabular}

Hazard ratio $(95 \% \mathrm{Cl})$ or $\mathrm{p}$-value

\begin{tabular}{l}
\hline Patients $\mathbf{n}$ \\
Duration of therapy days mean \pm sD \\
Duration days median (interquartile range) \\
Duration $\mathbf{n}(\%)$ \\
$<3$ months \\
$3-6$ months \\
$>6$ months \\
Symptomatic pulmonary embolism \\
Recurrent deep vein thrombosis \\
Major bleeding \\
Sites of major bleeding \\
Gastrointestinal \\
Retroperitoneal \\
Non-major bleeding \\
Death \\
Causes of death \\
Disseminated malignancy \\
Infection \\
Respiratory insufficiency \\
Ischaemic stroke \\
Liver insufficiency \\
Pulmonary embolism \\
Bleeding \\
Multi-organ failure \\
Unknown
\end{tabular}

\begin{tabular}{|c|c|c|c|c|}
\hline & 136 & & 93 & \\
\hline & $242 \pm 310$ & & $303 \pm 395$ & \\
\hline & $134(47-302)$ & & $155(45-463)$ & \\
\hline & $49(36)$ & & $37(40)$ & 0.581 \\
\hline & $32(24)$ & & $12(13)$ & 0.060 \\
\hline & $55(40)$ & & $44(47)$ & 0.342 \\
\hline 12 & $13.3(7.21-22.6)$ & 2 & $2.60(0.44-8.57)$ & $5.13(1.30-33.8)$ \\
\hline 9 & $9.97(4.86-18.3)$ & 3 & $3.89(0.99-10.6)$ & $2.56(0.72-11.7)$ \\
\hline 3 & $3.34(0.85-9.10)$ & 2 & $2.60(0.44-8.59)$ & $1.29(0.19-10.8)$ \\
\hline 3 & $3.34(0.85-9.10)$ & 1 & $1.30(0.07-6.41)$ & $2.57(0.27-67.7)$ \\
\hline 0 & & 1 & $1.30(0.06-6.40)$ & \\
\hline 2 & $2.22(0.37-7.35)$ & 2 & $2.60(0.44-8.58)$ & $0.86(0.09-8.22)$ \\
\hline 68 & $75.3(58.9-94.9)$ & 16 & $20.8(12.3-33.0)$ & $3.63(2.14-6.44)$ \\
\hline 53 & $58.7(44.4-76.2)$ & 9 & $11.7(5.70-21.4)$ & $5.03(2.57-10.8)$ \\
\hline 2 & $2.22(0.37-7.32)$ & 1 & $1.30(0.06-6.40)$ & $1.71(0.13-50.3)$ \\
\hline 3 & $3.32(0.85-9.04)$ & 0 & & \\
\hline 1 & $1.11(0.06-5.46)$ & 1 & $1.30(0.06-6.40)$ & $0.85(0.02-33.3)$ \\
\hline 1 & $1.11(0.06-5.46)$ & 1 & $1.30(0.06-6.40)$ & $0.85(0.02-33.3)$ \\
\hline 1 & $1.11(0.06-5.46)$ & 0 & & \\
\hline 0 & & 1 & $1.30(0.06-6.40)$ & \\
\hline 0 & & 1 & $1.30(0.06-6.40)$ & \\
\hline 3 & $3.32(0.85-9.04)$ & 2 & $2.60(0.44-8.57)$ & $1.28(0.19-10.8)$ \\
\hline
\end{tabular}


TABLE 6 Multivariable analysis for major bleeding and for symptomatic pulmonary embolism

\begin{tabular}{|c|c|c|c|c|}
\hline & \multicolumn{2}{|l|}{ Major bleeding } & \multicolumn{2}{|c|}{$\begin{array}{c}\text { Symptomatic } \\
\text { pulmonary embolism }\end{array}$} \\
\hline & Hazard ratio $(95 \% \mathrm{CI})$ & p-value & Hazard ratio $(95 \% \mathrm{CI})$ & p-value \\
\hline \multicolumn{5}{|l|}{ Underlying diseases } \\
\hline Creatinine clearance $<30 \mathrm{~mL} \cdot \mathrm{min}^{-1}$ & $3.61(1.14-11.5)$ & 0.029 & & \\
\hline Anaemia & $1.96(0.98-2.55)$ & 0.059 & & \\
\hline WBC $>11000$ cells $\mu \mathrm{L}^{-1}$ & $3.03(1.55-5.93)$ & 0.001 & & \\
\hline \multicolumn{5}{|l|}{ Cancer characteristics } \\
\hline With metastases & $2.35(1.15-4.79)$ & 0.019 & & \\
\hline Colorectal cancer & & & $0.23(0.06-0.90)$ & 0.035 \\
\hline Ovarian cancer & $5.38(1.69-17.1)$ & 0.004 & & \\
\hline Renal cancer & $4.23(1.24-14.4)$ & 0.021 & & \\
\hline On anticoagulant therapy & $7.69(4.00-14.3)$ & $<0.001$ & $0.23(0.10-0.54)$ & 0.001 \\
\hline
\end{tabular}

number of included patients, the strict and identical diagnostic criteria for incidental pulmonary embolism and the reporting of objectively established outcomes (major bleeding and symptomatic pulmonary embolism). Additionally, the population-based sample we used describes the effects of anticoagulant therapy in "real world" clinical care, as opposed to in a protocol driven randomised trial, and enhances the generalisability of our findings.

In summary, cancer patients with incidental pulmonary embolism have a high risk for recurrent pulmonary embolism if they do not receive anticoagulant therapy, but have a high risk for bleeding complications as well during the course of anticoagulation. Hence, the risk/benefit ratio of anticoagulation is uncertain and must be evaluated in further studies.

\section{Acknowledgements}

We would like to thank the RIETE Registry Coordinating Center, S \& H Medical Science Service, for their quality control data, logistic and administrative support and S. Ortiz (Universidad Autónoma de Madrid) and statistical advisor, S \& H Medical Science Service, for the statistical analysis of the data presented in this paper.

Members of the RIETE Group: Spain: P. Agudo, M.A. Aibar, J.I. Arcelus, E. Artajona, A. Ballaz, R. Barba, M. Barrón, B. Barrón-Andrés, J. Bascuñana, A. Blanco-Molina, I. Cañas, I. Casado, C. Casillas, N. Castejón-Pina, J. de Miguel, J. del Toro, S. Díaz, J.A. Díaz-Peromingo, C. Falgá, C. Fernández-Capitán, C. Font, L. Font, P. Gallego, F. García-Bragado, M. García-Rodenas, V. Gómez, J. González, E. Grau, A. Grimón, L. Guirado, J. Gutiérrez, G. Hernández, L. Hernández-Blasco, V. Isern, L. Jara-Palomares, M.J. Jaras, D. Jiménez, R. Jiménez, J.L. Lobo, L. López-Jiménez, R. López-Reyes, J.B. López-Sáez, M.A. Lorente, A. Lorenzo, O. Madridano, A. Maestre, P.J. Marchena, M. Martín, J.M. Martín-Antorán, F. Martín-Martos, M. Monreal, M.V. Morales, D. Nauffal, J.A. Nieto, S. Nieto, M.J. Núñez, M. Odriozola, S. Otalora, R. Otero, A. Ovejero, B. Pagán, J.M. Pedrajas, C. Pérez, M.L. Peris, I. Pons, J.A. Porras, O. Reig, A. Riera-Mestre, A. Rivas, C. Rodríguez, M.A. Rodríguez-Dávila, V. Rosa, N. Ruiz-Giménez, C. Ruiz-Martínez, J.C. Sahuquillo, M.C. Sala, A. Sampériz, R. Sánchez, O. Sanz, S. Soler, J.M. Suriñach, C. Tolosa, J. Trujillo-Santos, F. Uresandi, B. Valero, R. Valle, A. Vargas, J. Vela, G. Vidal, C. Vilar, J. Villalta, B. Xifre. Belgium: T. Vanassche, P. Verhamme. Canada: P. Wells. Czech Republic: J. Hirmerova, R. Malý, T. Tomko. Ecuador: G. Celis, E. Salgado, G.T. Sánchez. France: L. Bertoletti, A. Bura-Riviere, D. Farge-Bancel, A. Hij, I. Mahé, A. Merah, I. Quere. Greece: M. Papadakis. Israel: A. Braester, B. Brenner, I. Tzoran. Italy: A. Apollonio, G. Barillari, A. Bertone, F. Bilora, E. Bucherini, M. Ciammaichella, F. Dentali, P. Di Micco, P. D’Onofrio, R. Duce, P. Ferrazzi, E. Grandone, G. Lessiani, C. Lodigiani, D. Mastroiacovo, F. Pace, R. Pesavento, M. Pinelli, R. Poggio, P. Prandoni, M. Rosa, L. Rota, E. Tiraferri, D. Tonello, A. Tufano, U. Venturelli, A. Visonà, B. Zalunardo. Latvia: A. Belovs, K. Sablinski, A. Skride. Portugal: A. Barbosa, J.L. Ribeiro, M.S. Sousa. Macedonia: M. Bosevski, M. Zdraveska. Switzerland: H. Bounameaux, L. Mazzolai.

Coordinator of the RIETE Registry: M. Monreal; RIETE Steering Committee Members: H. Decousus, P. Prandoni and B. Brenner; RIETE National Coordinators: R. Barba (Spain), P. Di Micco (Italy), L. Bertoletti (France), I. Tzoran (Israel), A. Reis (Portugal), M. Bosevski (Macedonia), H. Bounameaux (Switzerland), R. Malý (Czech Republic), P. Wells (Canada) and M. Papadakis (Greece); RIETE Registry Coordinating Center: S \& H Medical Science Service.

Author roles were as follows. M. Peris contributed to the design, analysis, interpretation of data, collected patients and approved the final version of the article. D. Jiménez contributed to the design, analysis, interpretation of data, collected patients and approved the final version of the article. A. Maestre contributed to the design, analysis, interpretation of data, collected patients and wrote the article. C. Font contributed to the interpretation of data, collected patients and approved the final version of the article. A.J. Tafur contributed to the interpretation of data and approved the final version of the article. L. Mazzolai contributed to the interpretation of data, collected patients and approved the final version of the article. B. Xifre collected patients and approved the final version of the article. A. Skride collected patients and approved the final version of the article. F. Dentali collected patients and approved the final version of the article. M. Monreal contributed to the design, analysis and interpretation of data, collected patients, wrote the article and obtained funding. 


\section{References}

1 Gosselin MV, Rubin GD, Leung AN, et al. Unsuspected pulmonary embolism: prospective detection on routine helical CT scans. Radiology 1998; 208: 209-215.

2 Dentali F, Ageno W, Becattini C, et al. Prevalence and clinical history of incidental, asymptomatic pulmonary embolism: a meta-analysis. Thromb Res 2010; 125: 518-522.

3 Kearon C, Akl EA, Comerota AJ, et al. Antithrombotic therapy for VTE disease: Antithrombotic therapy and prevention of Thrombosis, 9th ed: American College of Chest Physician Evidence-Based Clinical Practices Guidelines. Chest 2012; 141: e419S-e494S.

4 Lyman G, Khorana AA, Kuderer NM, et al. Venous thromboembolism prophylaxis and treatment in patients with cancer: American Society of Clinical Oncology clinical practice guideline update. J Clin Oncol 2013; 31: 2189-2204.

5 den Exter PL, Hooijer J, Dekkers OM, et al. Risk of recurrent venous thromboembolism and mortality in patients with cancer incidentally diagnosed with pulmonary embolism: a comparison with symptomatic patients. J Clin Oncol 2011; 29: 2405-2409.

6 Shinagare $\mathrm{AB}$, Okajima Y, Oxnard GR, et al. Unsuspected pulmonary embolism in lung cancer patients: comparison of clinical characteristics and outcome with suspected pulmonary embolism. Lung Cancer 2012; 78 : 161-166.

7 Douma RA, Kok MGM, Verberne LM, et al. Incidental venous thromboembolism in cancer patients: prevalence and consequence. Thromb Res 2010; 125: e306-e309.

8 Engelke C, Rummeny EJ, Marten K. Pulmonary embolism at multi-detector row CT of chest: one-year survival of treated and untreated patients. Radiology 2006; 239: 563-575.

9 O'Connell CL, Boswell WD, Duddalwar V, et al. Unsuspected pulmonary emboli in cancer patients: Clinical correlates and relevance. J Clin Oncol 2006; 24: 1712-1719.

10 Gladish GW, Choe DH, Marom EM, et al. Incidental pulmonary emboli in oncology patients: Prevalence, CT evaluation, and natural history. Radiology 2006; 40: 246-255.

11 Cronin CG, Lohan DG, Keane M, et al. Prevalence and significance of asymptomatic venous thromboembolic disease found on oncologic staging CT. Am J Roentgenol 2007; 189: 162-170.

12 Browne AM, Cronin CG, English $\mathrm{C}$, et al. Unsuspected pulmonary emboli in oncology patients undergoing routine computed tomography imaging. $J$ Thorac Oncol 2010; 5: 798-803.

13 Font C, Farrús B, Vidal L, et al. Incidental versus symptomatic venous thrombosis in cancer: a prospective observational study of 340 consecutive patients. Ann Oncol 2011; 22: 2101-2106.

14 Soler S, Delgado C, Ballaz A, et al. Unsuspected pulmonary embolism in patients with cancer. Thromb Res 2012; 129 Suppl 1: S16-S19.

15 van der Hulle T, den Exter PL, Planquette B, et al. Risk of recurrent venous thromboembolism and major haemorrhage in cancer-associated incidental pulmonary embolism amongst treated and untreated patients: a pooled analysis of 926 patients. J Thromb Haemost 2016; 14: 105-113.

16 Monreal M, Falgá C, Valdés M, et al. Fatal pulmonary embolism and fatal bleeding in cancer patients with venous thromboembolism: Findings from the RIETE Registry. J Thromb Haemost 2006; 4: 1950-1956.

17 Ruíz-Gimenez N, Suárez C, González R, et al. Predictive variables for major bleeding events in patients presenting with documented acute venous thromboembolism. Findings from the RIETE Registry. Thromb Haemost 2008; 100: 26-31.

18 Nieto JA, Solano R, Ruíz-Ribó MD, et al. Fatal bleeding in patients receiving anticoagulant therapy for venous thromboembolism: Findings from the RIETE Registry. J Thromb Haemost 2010; 8: 1216-1222.

19 Laporte S, Mismetti P, Decousus H, et al. Clinical predictors for fatal pulmonary embolism in 15,520 patients with venous thromboembolism: Findings from the Registro Informatizado de la Enfermedad Tromboembolica Venosa (RIETE) Registry. Circulation 2008; 117: 1711-1716.

20 Khorana AA, O'Connell C, Agnelli G, et al. Incidental venous thromboembolism in oncology patients. J Thromb Haemost 2012; 10: 2602-2604. 